\title{
Correction to: Modelling root system development for anchorage of forest trees up to the mature stage, including acclimation to soil constraints: the case of Pinus pinaster
}

\author{
Clément Saint Cast • Céline Meredieu • Pauline Défossez • Loïc Pagès • Frédéric Danjon (D)
}

Published online: 29 July 2019

(C) Springer Nature Switzerland AG 2019

Correction to: Plant and Soil (2019) 439: 405-430

https://doi.org/10.1007/s11104-019-04039-4

Owing to an error in the conversion of the original file, in figure 10, root systems a1, a2, b1 and b2 were represented too thick. The correct version of figure 10 is reproduced below.

Publisher's note Springer Nature remains neutral with regard to jurisdictional claims in published maps and institutional affiliations.

The online version of the original article can be found at https://doi.org/10.1007/s11104-019-04039-4

C. Saint Cast · F. Danjon $(\bowtie)$

BIOGECO, INRA, Univ. Bordeaux, 33610 Cestas, France

e-mail: frederic.danjon@inra.fr

C. Saint Cast · P. Défossez

ISPA, INRA, Bordeaux Sciences Agro, 33140 Villenave d'Ornon,

France

C. Meredieu

UEFP, INRA, 33610 Cestas, France

L. Pagès

PSH, INRA, 84914 Avignon, France 


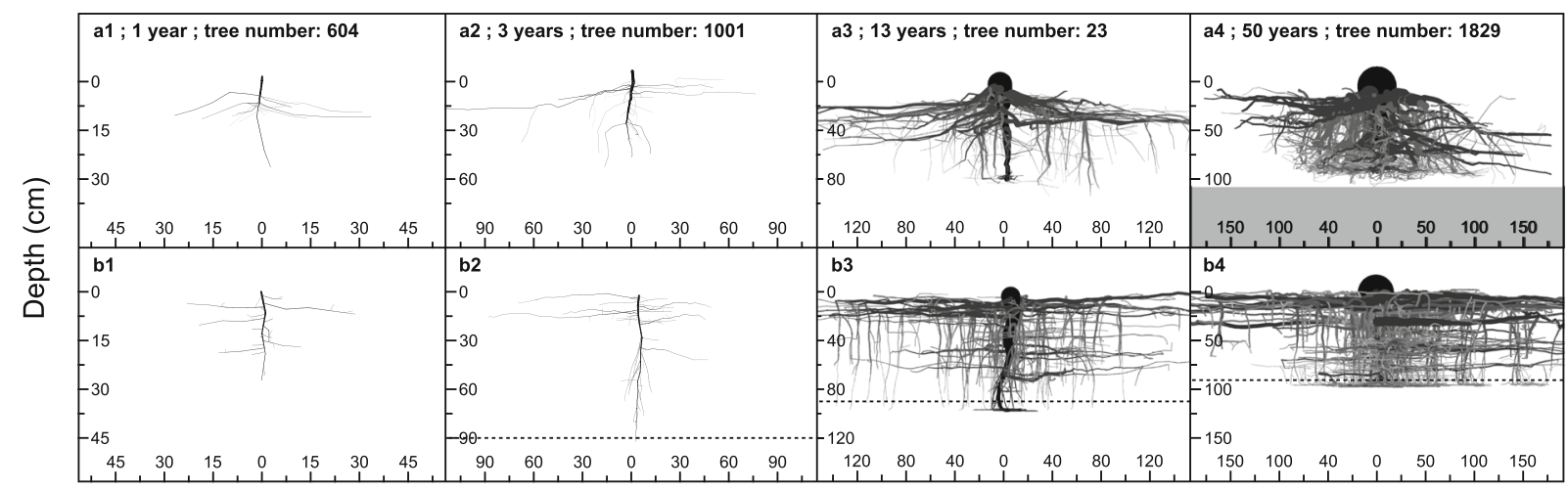

Radial distance $(\mathrm{cm})$

Fig. 10 Examples of observed (top, a) and simulated (bottom, b) root systems over (1) one, (2) three, (3) thirteen, and (4) fifty years. For observed tree 1829 (a4), the maximum depth is indicated by the upper limit of the grey area. For simulated trees, the upper limit of the cemented horizon is indicated by the dotted horizontal line (90 cm depth - b2, b3 and b4) 